\title{
A Cross Sectional, Analytical Study of the Morbidity Pattern among Boys Residing in Social Welfare Hostels in Tirupati Town, A. P.
}

\author{
Karamthoti Ravi Naik ${ }^{1}$, K. Srinivasan², B. Prameela³, G. Ravi Prabhu, K. Ashok Kumar Reddy ${ }^{5}$ \\ ${ }^{1}$ Department of Community Medicine, Government Medical College, Anantapuramu, Andhra Pradesh, \\ India. ${ }^{2}$ Department of Community Medicine, Government Medical College, Anantapuramu, Andhra \\ Pradesh, India. ${ }^{3}$ Department of Anatomy, Kurnool Medical College, Kurnool, Andhra Pradesh, \\ India. ${ }^{4}$ Department of Community Medicine, S. V. Medical College, Tirupati, Andhra Pradesh, India. \\ ${ }^{5}$ Department of Community Medicine, S. V. Medical College, Tirupati, Andhra Pradesh, India.
}

\section{ABSTRACT}

\section{BACKGROUND}

The role of hostels in the educational advancement of backward classes is long recognized. In closed homes like hostels, the morbid conditions especially infectious diseases like skin diseases and respiratory diseases tend to rapidly spread among others and become difficult to control. There is increased nutritional demand in this age group because of pubertal changes. It has been found that several school children especially from socially backward sections of the community suffer from nutritional health problems as well as other physical health problems. We wanted to evaluate the morbidity pattern among boys residing in social welfare hostels.

\section{METHODS}

This is a cross sectional, analytical study to determine the morbidity pattern among boys residing in social welfare hostels. This present study was conducted from August 2013 to July 2014 among boys residing in three welfare hostels, one each for scheduled castes, scheduled tribes and backward classes in Tirupati town.

\section{RESULTS}

The common prevalent morbid conditions found were skin disorders (46.4\%), nutritional disorders $(43.1 \%)$, eye diseases $(29.0 \%)$, respiratory diseases $(15.3 \%)$ gastrointestinal diseases (13.6\%), ENT diseases (9.5\%,), musculoskeletal conditions $(1.0 \%)$, and other diseases $(5.7 \%)$.

\section{CONCLUSIONS}

Health education and increasing the nutritional supplements improve the health of children with regard to personal hygiene and common diseases. Provision of necessary materials like soaps, oils etc., under supervision of hostel staff will go a long way in controlling these infections.

\section{KEY WORDS}

Morbidity Pattern, Hostel Children, Skin Disorders, Nutritional Disorder, Clinical Anaemia
Corresponding Author:

Dr. K. Srinivasan

Professor and HOD

Department of Community Medicine,

Government Medical College,

Anantapuramu, Andhra Pradesh, India.

E-mail: Srinivasan_@yahoo.com

DOI: $10.14260 / \mathrm{jemds} / 2020 / 122$

Financial or Other Competing Interests: None.

How to Cite This Article:

Naik KR, Srinivasan K, Prameela B, et al. A cross sectional, analytical study of the morbidity pattern among boys residing in social welfare hostels in Tirupati town, $A$. P. J. Evolution Med. Dent. Sci. 2020;9(08): 544-548, DOI: 10.14260/jemds/2020/122

Submission 20-11-2019,

Peer Review 28-01-2020,

Acceptance 04-02-2020,

Published 24-02-2020.

\section{(i)}




\section{BACKGROUND}

The role of hostels in the educational advancement of backward classes is long recognized. At present, there are 2,358 social welfare hostels for scheduled castes functioning in Andhra Pradesh at the rate of 100 per each hostel with a sanctioned strength of 2,35,800 students of which scheduled caste children comprise $70 \%$ of the inmates. ${ }^{1}$ There are 1,429 hostels for backward classes with a sanctioned strength of 1 , 42,900 students and 442 hostels for tribal children with a sanctioned strength of 44,200 students. 2,3 The Departments of Education, Tribal welfare and backward classes welfare are concerned with the maintenance of these hostels. School age is considered to be very important in terms of its impact on the physical, mental as well as social development of children. With increased nutritional demands during this age group because of pubertal changes, it has been found commonly that several school children especially from socially backward sections of the community suffer from nutritional health problems as well as other physical health problems. Thus many studies carried out in various parts of India had reported a high proportion of morbid conditions as well as malnutrition and other nutritional health problems among school going children. In closed homes like hostels, the morbid conditions especially infectious diseases like skin diseases, respiratory diseases tend to rapidly spread among others and difficult to control. In this context, the present study was taken up among children residing in social welfare hostels in Tirupati town of Andhra Pradesh. This study focuses on morbidity status of children.

\section{METHODS}

This present study was conducted from August 2013 to July 2014 among boys residing in three welfare hostels, one each for scheduled castes, scheduled tribes and backward classes in Tirupati town. After obtaining institutional ethical committee approval, permission from the Deputy Director of Social Welfare, Assistant tribal welfare officer and Assistant backward classes welfare officer was obtained for conducting the study. The wardens were interviewed, and hostel registers were used to secure information regarding the number of residential children, their ages and particulars regarding in hostels etc. Simple random technique, lottery method was used for sampling. Study Design: Cross- Sectional study, Analytical. Study Setting: Three welfare hostels in urban area of Tirupati, one each for scheduled castes, scheduled tribes and backward classes. Study Subjects: A total 524 boys residing in three welfare hostels in Tirupati town. In the present study, 275 students out of 280 in scheduled caste hostel, 140 out of 152 and 109 out of 124 in backward class and scheduled tribe hostel formed the subjects of the study. Simple random method used for sampling. All the inmates of the hostels formed the study population. The age of the students ranged from 6 to 16 years.

\section{Inclusion Criteria}

All those children available at the time of the study and who have given consent for the study.

\section{Exclusion Criteria}

Those children who were not available even after 3 visits to the institution and who had not given consent for the study. It was found that 524 out of 554 inmates in the hostel (around 95\%) had participated in the study.

\section{Study period}

6 months for data collection from September 2013 to February 2014 and 3 months for data analysis and 3 months for report writing from May 2014 to July 2014. After conducting a pilot study. The collection of data done by a predesigned, pre-tested interview schedule. The clinical examination is carried out by using, weighing machine, measuring tape, and Snellen's chart, stethoscope, sphygmomanometer etc. Three visits were made to examine the study subjects. Every child was examined physically from head to toe and any signs and symptoms of illness were recorded. Enquiry was made about the duration of stay in the hostel, practices regarding personal hygiene and occurrences of ailment during the study. Enquiry was made about the health problems and occurrence of any ailment during previous two weeks. Clinical Anaemia was diagnosed by clinical signs such as pallor of the conjunctiva/tongue. Worm infestation was diagnosed on the basis of history and asking questions. Hearing was assessed by Rinne's test. Snellen's chart was used to assess the visual acuity. Oral cavity was examined for any abnormal pigmentation of teeth, caries, cavities, glossitis and ulcers of mouth or tongue. Skin diseases were diagnosed by magnifying lens.

\section{Limitations}

Those children who were not available and not willing to participate in the study could not be included in study. Similarly, absentees and dropouts could not be included in the study. Since this is a cross sectional, analytical study, the correlation if any between health status of children and their performance at schools could not be studied. Incidence rates of morbidity disorders could not be calculated since this is a cross sectional, analytical study. Since this study is limited by its small sample size, the results may therefore cannot be generalized. A large sample size of children with more number of hostels could have given better results.

\section{Statistical Analysis}

Data collected in hostels were entered in Microsoft Excel2007 and analysed using epi info 3.2.1 version. Descriptive statistical measure such as percentage was used. For testing the statistical significance of proportions, chi-square test was used. Adjacent rows and columns were combined in cases where the expected value is less than 5 in any cell. BMI was categorized by using Z score WHO-2007 growth reference chart for BMI for age standards for children between 2 and 19 years for boys. In all cases, a probability value of less than 0.05 was considered as statistically significant.

\section{Criteria for the Conditions}

Case definitions: Morbidities were broadly categorized into those related to the scalp and hair, skin, eyes, ear, nose and throat (ENT), oral cavity, respiratory system, cardiovascular system, gastrointestinal system, central nervous system. 
Diseases of the scalp and hair: Seborrhea capitis (dandruff): Presence, in varying amounts, of white or grey scales in the hair of the scalp. Alopecia areata or totalis: Patchy loss and total loss of hairs of hair on scalp Unhealthy texture of hairs. Diseases of the skin: Pityriasis Alba: Presence of ill-defined, scaly, faintly erythematous patches especially on the face. Scabies: Presence of itchy, thin, irregular burrowing lesions made of tiny blisters and bumps on the skin especially, in web spaces, arm pits, waist, inside of wrist etc. Pyoderma: Any purulent lesions on the skin that may include, furuncle, pustule, impetigo, boil etc Contact dermatitis: Inflammatory lesions on the skin coming in contact with external substances such as, soap, cosmetics, mud/cement, watch etc., characterized by, red, crusty, scaly, itchy patches. Photodermatitis: Presence of superficial, reddish, itchy, raised lesions on sun exposed part of the body. Acne: An eruption, predominantly of the face, upper back and chest, composed of comedones, cysts, papules and pustules on an inflammatory base Urticaria: A transient appearance of slightly elevated patches (wheals) which are redder or paler than the surrounding skin and often attended by severe itching. Pallor: Paleness of, palpebral conjunctiva, palm/soles, dorsum of tongue or all of them, suggestive of anaemia. Diseases of eyes: Refractive error: diagnosed by Snellen's chart Conjunctivitis: Acute onset reddish coloration of one or both the eyes associated with watering, pain, itching and thick discharge Xerosis of conjunctiva: Dry, lusterless bulbar conjunctiva Bitot spots: Gray, triangular spots on the conjunctiva Acute dacryocystitis: Pain, redness, tearing and swelling at the inner corner of the eye by the nose. Diseases of ENT: Acute suppurative otitis media: Acute onset ear pain, typically presenting as pain deep inside the ear canal, with mild hearing impairment, pain subsiding after initiating of ear discharge usually associated with systemic symptoms of fever, malaise, fatigability Chronic suppurative otitis medicine: Chronic inflammation of the middle ear and mastoid cavity, which presents with recurrent ear discharge, hearing impairment usually lasting for more than 2 weeks (WHO) Acute respiratory infection (ARI): Children with any one or combinations of symptoms and signs such as cough and cold, running or blocked nose, sore throat, rapid breathing, noisy breathing, stops feeding and or drinking, chest in drawing etc., A new episode was taken as one occurring in an individual who had been free of symptoms for at least 3 consecutive days or more as per WHO (1997) definition of ARI. Acute tonsillitis: Bilaterally red and enlarged tonsils with purulent discharge and yellowish membrane on the surface of tonsils associated with fever, pain or difficulty while swallowing Acute sinusitis: Pain, tenderness, swelling and pressure around eyes, cheeks, nose or forehead associated with headache, fever and other features of systemic inflammation Deviated nasal septum: Deviation of the nasal septum with narrowing and congestion of opposite nasal cavity Similar way other conditions such as epistaxis, external abnormalities were also defined. Diseases of the oral cavity: Gingivitis, cheilitis, glossitis, angular stomatitis: Swelling and reddishness of gums, lips, angles of mouth and tongue Dental caries and impacted teeth were diagnosed based on the observations. Respiratory tract: Lower respiratory tract infection: History of cough, fever, symptoms for at least 3 consecutive days or more Bronchial asthma: History of cough, recurrent episodes of breathlessness, wheezes, with bilateral widespread rhonchi all over lung fields. Diseases of the cardiovascular system: A child with history of chest pain on exertion, exercise intolerability, breathlessness on exertion with murmurs in any of the four areas of pre-cardium. Diseases of Gastrointestinal system: History of abdominal pain, nausea, vomiting, loose stools, pus/blood in stools, with epigastric tenderness, hepatomegaly and splenomegaly on examination. Diseases of Genitourinary tract: Urinary tract infection: History of fever, burning micturition and vomiting, increased frequency of micturition. Diseases of Central Nervous System: History of unilateral headache with vomiting, convulsions, mental retardation, speech deformities, paralysis of any of the limbs.

\section{RESULTS}

\begin{tabular}{|c|c|c|}
\hline Variable & No. of Subjects & Percentage \\
\hline \multicolumn{3}{|c|}{ Age Group of Children (years) } \\
\hline $8-10$ & 77 & 14.7 \\
\hline $11-13$ & 203 & 38.7 \\
\hline $14-16$ & 244 & 46.6 \\
\hline \multicolumn{3}{|c|}{ Class of Study } \\
\hline $6-8$ & 85 & 16.2 \\
\hline $10-$ Sep & 270 & 51.5 \\
\hline \multicolumn{3}{|c|}{ Social Category } \\
\hline Scheduled caste & 231 & 32.3 \\
\hline Scheduled tribe & 117 & 44.1 \\
\hline Backward classes & 154 & 22.3 \\
\hline Other castes & 22 & 4.2 \\
\hline C C &
\end{tabular}

Table 1. Age, Class and Social Category Distribution of Subjects ( $N=524)$.

It was found that a majority of children belonged to 14-16 years age group (46.6\%), studying between 6-8 classes (51.5\%) and to scheduled caste (44.1\%)

\begin{tabular}{|c|c|c|}
\hline Morbidity Disorder & Number of subjects & Percentage \\
\hline Skin disorders & 243 & 46.4 \\
\hline Nutritional disorders & 226 & 43.1 \\
\hline Eye disorders & 152 & 29 \\
\hline Respiratory disorders & 80 & 15.3 \\
\hline Gastrointestinal disorders & 71 & 13.6 \\
\hline ENT disorders & 50 & 9.5 \\
\hline Musculoskeletal disorders & 5 & 1 \\
\hline Other disorders & 30 & 5.7 \\
\hline \multicolumn{3}{|c|}{ Table 2. Morbidity Disorders among Subjects $(N=524)$} \\
\hline \multicolumn{3}{|c|}{$\begin{array}{l}\text { The commonest morbidity disorders in children were skin disorders (46.4\%), } \\
\text { nutritional disorders (43.1) and eye disorders (29.0\%) }\end{array}$} \\
\hline Other Disorders & Number of Subjects & Percentage \\
\hline Bed wetting & 13 & 2.5 \\
\hline Adventitious sounds in heart & 6 & 1.2 \\
\hline Wasting & 6 & 1.2 \\
\hline Hydrocoele & 2 & 0.4 \\
\hline Epilepsy & 2 & 0.4 \\
\hline Cervical lymphadenopathy & 2 & 0.4 \\
\hline Hernia (umbilical) & 1 & 0.2 \\
\hline \multicolumn{3}{|c|}{ Table 3. Other Disorders among Subjects $(N=524)$} \\
\hline $\begin{array}{l}\text { The other disorders found we } \\
(1.2 \%) \text { and wasting }(1.2 \%) . \mathrm{BC}\end{array}$ & $\begin{array}{l}\text { ed wetting ( } 2.5 \%) \text {, adve } \\
\text { car was seen in } 55.2 \% \mathrm{c}\end{array}$ & $\begin{array}{l}\text { us sounds in heart } \\
\text { an. }\end{array}$ \\
\hline
\end{tabular}

Majority of the children were in the age group of 11-16 years; scheduled caste children constituted a large proportion (85.3\%). The major prevalent morbid conditions among boys were skin disorders (46.4\%), nutritional 
disorders (43.1) eye disorders (29.0) respiratory disorders (15.3) gastrointestinal disorders (13.6). (Table I).

\begin{tabular}{|c|c|c|c|}
\hline Sl. No. & Skin Disorder & Number of Subjects & Percentage \\
\hline 1. & Pediculosis & 152 & 29.0 \\
\hline 2. & Scabies & 88 & 16.8 \\
\hline 3. & Tinea & 39 & 7.4 \\
\hline 4. & Pyoderma & 24 & 4.6 \\
\hline 5. & Skin ulcers & 16 & 3.1 \\
\hline 6. & Hypo pigmented patches & 5 & 1.0 \\
\hline 7. & Hansen's disease & 2 & 0.4 \\
\hline \multicolumn{3}{|c|}{ Table 4. Skin Disorders among Subjects (N=524) } \\
\hline $\begin{array}{l}\text { The common skin disorders were found to be pediculosis (29.0\%), scabies (16.8\%), } \\
\text { tinea (7.4\%) and pyoderma (4.6\%) }\end{array}$
\end{tabular}

\begin{tabular}{|c|c|c|c|c|}
\hline \multirow{2}{*}{ Morbidity Disorder } & \multicolumn{3}{|c|}{ Age Group (years) } & \multirow{2}{*}{ p } \\
\cline { 2 - 4 } & $\mathbf{8 - 1 0}$ & $\mathbf{1 1 - 1 3}$ & $\mathbf{1 4 - 1 6}$ & \\
\cline { 2 - 4 } & $\mathbf{( N = 7 7 )}$ & $\mathbf{( N = 2 0 3 )}$ & $\mathbf{( N = 2 4 4 )}$ & \\
\hline Skin disorders & $47(61.0)$ & $102(50.3)$ & $94(38.5)$ & $<0.001 ; \mathrm{S}$ \\
\hline Nutritional disorders & $38(49.4)$ & $97(47.8)$ & $91(37.3)$ & $0.04 ; \mathrm{S}$ \\
\hline Eye disorders & $17(22.0)$ & $48(23.6)$ & $87(35.7)$ & $0.007 ; \mathrm{S}$ \\
\hline Respiratory disorders & $20(26.0)$ & $21(10.3)$ & $39(16.0)$ & $0.004 ; \mathrm{S}$ \\
\hline Gastrointestinal disorders & $12(15.6)$ & $27(13.3)$ & $32(13.1)$ & $0.85 ; \mathrm{NS}$ \\
\hline ENT disorders & $7(9.1)$ & $22(10.8)$ & $21(8.6)$ & $0.71 ; \mathrm{NS}$ \\
\hline Musculoskeletal disorders & $1(1.3)$ & $1(0.5)$ & $3(1.2)$ & --- \\
\hline Other disorders & $7(9.1)$ & $13(6.4)$ & $10(4.1)$ & $0.22 ;$ NS \\
\hline \multicolumn{7}{|c|}{ Table 5. Morbidity Disorders by Age Group of Subjects } \\
\hline $\begin{array}{l}\text { The prevalence of skin disorders, nutritional disorders and respiratory disorders } \\
\text { was found to be significantly higher in 8-10-year age group children compared to } \\
\text { other age groups. The prevalence of gastrointestinal disorders was also found to be } \\
\text { higher in 8-10 years, but the differences were not statistically significant. The } \\
\text { prevalence of eye disorders was found to be significantly higher in 14-16 years } \\
\text { children compared to other age groups. }\end{array}$ \\
\hline
\end{tabular}

\begin{tabular}{|c|c|c|c|c|}
\hline \multirow{3}{*}{ Morbidity Disorder } & \multicolumn{3}{|c|}{ Class of Study } & \multirow{3}{*}{$\mathbf{p}$} \\
\hline & \multirow{2}{*}{\begin{tabular}{|c|}
$3-5$ \\
$(N=85)$ \\
\end{tabular}} & \multirow{2}{*}{$\frac{6-8}{(N=270)}$} & \multirow{2}{*}{$\begin{array}{c}9-10 \\
(\mathrm{~N}=169)\end{array}$} & \\
\hline & & & & \\
\hline Skin disorders & $54(63.5)$ & $\begin{array}{c}136 \\
(50.4)\end{array}$ & $53(31.4)$ & $<0.001 ; \mathrm{S}$ \\
\hline Nutritional disorders & $43(50.6)$ & $\begin{array}{c}115 \\
(42.6)\end{array}$ & $68(40.2)$ & $0.28 ; \mathrm{NS}$ \\
\hline Eye disorders & $19(22.3)$ & $75(27.8)$ & $58(34.3)$ & $0.11 ; \mathrm{NS}$ \\
\hline Respiratory disorders & $22(25.9)$ & 30 (11.1) & $28(16.6)$ & $0.003 ; \mathrm{S}$ \\
\hline Gastrointestinal disorders & $14(16.5)$ & $37(13.7)$ & $20(11.8)$ & $0.59 ; \mathrm{NS}$ \\
\hline ENT disorders & $8(9.4)$ & $28(10.4)$ & $14(8.3)$ & $0.77 ; \mathrm{NS}$ \\
\hline Musculoskeletal disorders & $2(2.4)$ & $1(0.4)$ & $2(1.2)$ & ---- \\
\hline Other disorders & $7(8.2)$ & $18(16.7)$ & $5(3.0)$ & $0.68 ; \mathrm{NS}$ \\
\hline \multicolumn{5}{|c|}{ Table 6. Morbidity Disorders by Class of Study } \\
\hline \multicolumn{5}{|c|}{$\begin{array}{l}\text { The prevalence of skin disorders, nutritional disorders, respiratory disorders, } \\
\text { gastrointestinal disorders was higher in children studying 3-5 standards. The } \\
\text { statistical significance was however found with regard to skin disorders and } \\
\text { respiratory disorders. The prevalence of eye disorders was found to be slightly } \\
\text { higher in children in } 9-10 \text { standard, but the differences were not statistically } \\
\text { significant. Similarly, a slightly higher prevalence of ENT disorders was found in } \\
\text { 6-8 standard children but here also the differences were not statistically } \\
\text { significant. }\end{array}$} \\
\hline
\end{tabular}

\begin{tabular}{|c|c|c|c|c|c|}
\hline \multirow{4}{*}{$\begin{array}{l}\text { Morbidity } \\
\text { Disorder }\end{array}$} & \multicolumn{4}{|c|}{ Social Category } & \multirow{4}{*}{$\mathbf{p}$} \\
\hline & \multicolumn{3}{|c|}{\begin{tabular}{|l|l|} 
Scheduled Scheduled Backward \\
\end{tabular}} & \multirow{2}{*}{$\begin{array}{l}\text { Other } \\
\text { Castes }\end{array}$} & \\
\hline & Caste & Tribe & Classes & & \\
\hline & $\begin{array}{c}(\mathrm{N}=231) \\
(\%)\end{array}$ & $(\mathrm{N}=117)$ & $(\mathrm{N}=154)$ & $(\mathrm{N}=22)$ & \\
\hline Skin disorders & $114(49.4 \%)$ & $47(40.2)$ & $74(48.0)$ & $9(36.4)$ & $0.38 ; \mathrm{NS}$ \\
\hline Nutrition & $83(35.9)$ & $65(55.6)$ & $70(45.5)$ & $8(36.4)$ & $0.005 ; \mathrm{S}$ \\
\hline Eye dis & $60(26.0)$ & $29(24.8)$ & $58(37.7)$ & $5(22.7)$ & $0.04 ; S$ \\
\hline Respiratory disorders & 45 (19.5) & 20 (17.1) & $14(9.1)$ & $1(4.6)$ & $\begin{array}{c}* 0.007 ; \\
\text { S }\end{array}$ \\
\hline $\begin{array}{c}\text { Gastrointestinal } \\
\text { disorders }\end{array}$ & $48(20.8)$ & $10(8.6)$ & $12(7.8)$ & $1(4.5)$ & $\begin{array}{c}{ }^{*} 0.001 ; \\
\mathrm{S}\end{array}$ \\
\hline ENT disorders & $28(12.1)$ & $6(5.1)$ & $15(9.7)$ & $1(4.5)$ & $0.10 ; \mathrm{NS}$ \\
\hline $\begin{array}{c}\text { Musculoskeletal } \\
\text { disorders }\end{array}$ & $3(1.3)$ & $1(0.9)$ & $1(0.7)$ & $0(0.0)$ & --- \\
\hline Other disorders & $18(7.8)$ & $8(6.8)$ & $4(2.6)$ & $0(0.0)$ & $0.11 ; \mathrm{N}$ \\
\hline
\end{tabular}

Table 7. Morbidity Disorders by Social Category of Subjects

*In the calculation of chi-square value, the backward classes and other castes were combined to make a minimum expected value of 5 in all the cells.

The prevalence of nutritional disorders was found to be significantly higher in scheduled tribe children while the prevalence of eye disorders was found to be significantly higher in backward classes children. The prevalence of respiratory disorders and gastrointestinal disorders was found to be significantly higher in scheduled caste children. The prevalence of skin disorders and ENT conditions was found to be comparatively higher in scheduled caste children, but the differences were not statistically significant.

\section{DISCUSSION}

Children of welfare hostels come from the poorer sections of the society. The health problems of school age group children vary from place to place and several studies conducted in India and outside revealed that the main morbidity conditions, include infectious diseases, malnutrition, and helminthiasis, diseases of the skin, eye, ear and dental problems. ${ }^{4}$ In India, several studies have been carried out on the health status of school age children. These have largely been quantitative, and the reported morbidity included malnutrition (10.0-98.0\%), dental ailments (4.0-70.0\%), worm infestation (2.0-30.0\%), skin diseases (5.0-10.0\%), eye diseases (4.0-8.0\%), and anaemia (4.0-15.0\%). ${ }^{5}$

In the present study, the common prevalent morbidity were skin disorders (46.4\%), nutritional disorders (43.1\%), eye disorders (29.0\%), respiratory disorders (15.3\%), gastrointestinal disorders (13.5\%), ENT disorders (9.5\%), musculoskeletal disorders (1.0\%), and other disorders (5.7\%). The high prevalence of morbidity observed in the present study will interfere with the physical and mental development of children and contribute to scholastic backwardness. The common skin disorders in present study were found to be pediculosis $(29.0 \%)$, scabies (16.8\%), tinea (7.4\%) and pyoderma (4.6\%). Prevalence of skin disorders was found to be (46.4\%). A higher prevalence was found in study in an urban area of Meerut (59\%). ${ }^{6}$ Tirupati $(25.7 \%),{ }^{4}$ Ropar (23.2\%), ${ }^{7}$ Guntur $(22.9 \%)^{8}$ and Nellore (26.4\%). ${ }^{9} \mathrm{~A}$ very low prevalence among girls was reported in a study at Vizianagaram (16.0\%).10 The prevalence of scabies was found to be $(16.8 \%)$ while a study in Tirupati has found a high prevalence of (29.9\%). ${ }^{4}$ Similarly a high prevalence was found among scheduled castes in Chittoor district (28.9\%). ${ }^{11}$ A lower prevalence was however found in other caste children in Chittoor district study $(1.6 \%) 12$ while Nellore study reported a prevalence of $(16.8 \%)$ in girls. ${ }^{9}$ The prevalence of eye disorders was found to be $(29 \%)$. The prevalence of defective vision in the present study was found to be $(14.3 \%)$. Lower prevalence was reported in Delhi study (5.4\%) 13 and Tirupati study (4.4\%). 4 The prevalence of respiratory disorders in the present study was found to be (15.3\%) among which ARI was found to be (9.2\%). The Andhra Pradesh school health project survey 1996 reported a prevalence of $(4.8 \%)$ in children in Chittoor dist.12 Similar study conducted in Western Uttar Pradesh has found a comparable prevalence of $(7.1 \%) .{ }^{14}$ The prevalence of dental caries was found to be (15.1\%) A comparable prevalence of (16.1\%) was found in Delhi study. ${ }^{15}$ A lower prevalence of $6.9 \%$ was found in AP school health project survey at Chittor ${ }^{6}$ while a high prevalence was reported in scheduled caste children $(23.4 \%)$. The high prevalence of dental problems may be attributed to bad oral hygiene. A study at Vikarabad (AP) has found a high prevalence of dental caries (34.3\%). ${ }^{16} \mathrm{~A}$ very high prevalence of $(69.1 \%)$ was found in a study at Vadodara. History of passing worms in stools was reported among $8.2 \%$ subjects in the present study. Although a overall lower prevalence was reported by AP school health project survey (4.0\%),12,11 a high prevalence was reported in scheduled caste children (25.4\%). A higher prevalence was also reported in Guntur study (13.3\%).17 
While a study in Tirupati ${ }^{8}$ has found a very high prevalence of worm infestation in a sub-sample. The prevalence of anaemia in school children worldwide is $48 \%$ as reported by UNICEF report. ${ }^{18}$ The prevalence of clinical anaemia in the present study was found to be (7.3\%). A similar prevalence was found by AP School health project survey $(8.2 \%)$ in Chittoor district ${ }^{12}$ and in Guntur study (5.3\%). ${ }^{8}$ Similar high prevalence was found in Vizianagaram $(30.0 \%)^{10}$ and Nellore (41.1\%). ${ }^{9}$

\section{CONCLUSIONS}

In view of the high prevalence of morbidity among children, periodic medical examination of the inmates and treatment facilities should be organized and monitored systematically. Health education and increasing the nutritional supplements improve the health of children with regard to personal hygiene and common diseases. Provision of necessary materials like soaps, oils etc., under supervision of hostel staff will go a long way in controlling these infections.

\section{REFERENCES}

[1] Department of Social Welfare. Accessed on 25-10-13. www.APonlineorganisation _ schostels.

[2] Department of Backward Class Welfare. Accessed on 2510-13. www.APonlineorganisation_bchostels.

[3] Andhra Pradesh Tribal Welfare Department. Accessed on 25-10-13. Government of India Ministry of Law and Justice: Constitution of India. As modified up to the 1st December 2007: Fundamental rights. Free and compulsory education for-State to provide: 400 . www.aptribes.gov.in.

[4] Sivaiah T, Sitarama A. A study of health status profiles of children of welfare hostels in rural health centre, Tadikonda area of Guntur district. Int J Res Health Sci 2014;2(1):26-9.

[5] Saluja N, Garg S, Chopra H. Prevalence of morbidity and morbidity pattern in school children (5-11 yrs) in urban area of Meerut. The Internet Journal of Epidemiology 2010;9(2):15-8.

[6] Joshi N, Sujan SG, Joshi K, et al. Prevalence severity and relate factors of dental caries in school going children of
Vadodara city - an epidemiological study. J Int Oral Health 2013;5(4):35-9.

[7] Chabbra P, Garg S, Sharma N, et al. Health and nutritional status of boys aged 6-12 years in a children's observation home Delhi. Indian Journal of Public Health 1996;40(4):126-9.

[8] Gugwad R, Anjum M, Chowdary S, et al. Oral health status of the welfare hostel students in Vikarabad Town, Andhra Pradesh, India. WebmedCentral Dentistry 2012;3(11):WMC003828.

[9] Tania MK, Sandel J, Sukhla PL. Health status of urban school children in western Uttar Pradesh. Indian Journal of Paediatrics 1978;45(370):359-69.

[10] Yerpude PN, Jogdand KS, Jogdand M. A study of health status among school going adolescents in South India. Int J Health Sci Res 2013;3(11):8-12.

[11] Srinivasan K, Prabhu GR. A study of the morbidity status of the children in social welfare hostels in Tirupati town. Indian J Community Med 2006;31(3):170-2.

[12] Andhra Pradesh School Health Project: Special School Health check-up programme, Chittoor district report, 1996.

[13] Wasnik V, Rao BS, Rao D. A study of the health status of early adolescent girls residing in social welfare hostels in Vizianagaram district of Andhra Pradesh State, India. IJCRIMPH 2012;4(1):72-83.

[14] Gupta KB, Walia BNS. A longitudinal study of morbidity in children in a rural area of Punjab. Indian Journal of Pediatrics 1980;47:297-301.

[15] Ananthakrishnan S, Pani SP, Nalini P. Extent and pattern of health status of school age children. Vector Control Research Centre, ICMR, Pondicherry, India. A report. 2001.

[16] Kumar R, Dabas P, Mehra M, et al. Ocular morbidity amongst primary school children in Delhi. Health and Population 2007;30(3):222-9.

[17] Susmitha KM, Jyothi C, Prabakaran J. Morbidity pattern among the adolescent girls: a study in the social welfare hostels for scheduled castes, Nellore city, A.P, India. Nat J Res Com Med 2012;1(1):35-40.

[18] Stoltzfus RJ, Dreyfuss ML. Guidelines for the use of iron supplements to prevent and treat iron deficiency anaemia. Geneva, 1998. International Nutritional Anemia Consultative Group/ UNICEF/ WHO. Accessed on 21.10.14.

http://www.who.int/nutrition/publications/micronutri ents/guidelines_for_Iron_supplementation. 